\title{
COATING INFLUENCE ON ULTRASONIC THICKNESS MEASUREMENT RESULT
}

\author{
Morana Mihaljević, Hrvoje Cajner, Damir Markučič, Karlo Kožić
}
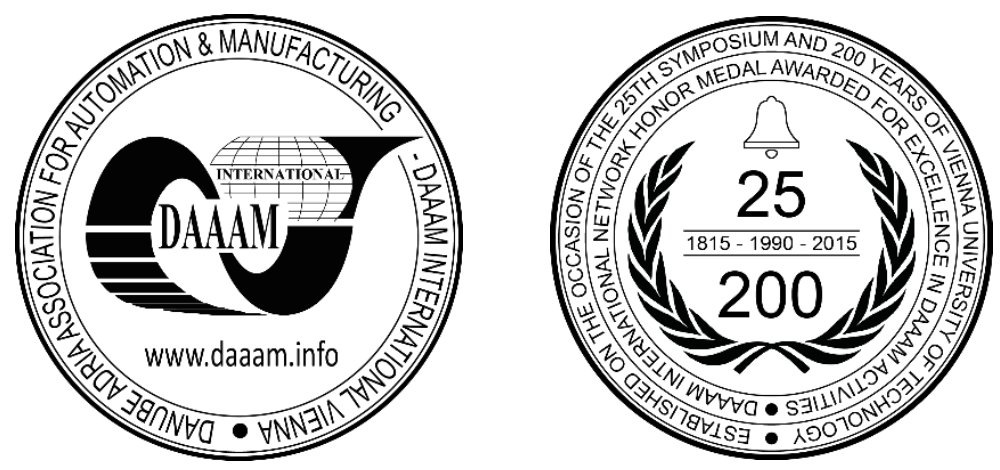

This Publication has to be referred as: Mihaljevic, M[orana]; Cajner, H[rvoje]; Markucic, D[amir] \& Kozic, K[arlo] (2018). Coating Influence on Ultrasonic Thickness Measurement Result, Proceedings of the 29th DAAAM International Symposium, pp.0341-0346, B. Katalinic (Ed.), Published by DAAAM International, ISBN 978-3-902734-20-4, ISSN 1726-9679, Vienna, Austria

DOI: $10.2507 / 29$ th.daaam.proceedings.049

\begin{abstract}
In this paper the Monte Carlo Simulation is presented and applied as a method for quantification of the coating influence on ultrasonic thickness measurement (UTM) results. UTM as a Non Destructive Testing (NDT) technique is commonly used for integrity assessment of components and the whole structures. It belongs to a field of measurement activities since the measurement result is shown quantitatively. Generally, a measurement result is complete only when it is followed up by a statement of the associated uncertainty. In order to evaluate the measurement uncertainty of ultrasonic thickness measurements all significant factors and their interactions should be taken into account. One of the influence factor is coating over the base material. In some cases the coating can be removed before the beginning of measurement procedure, but in some cases the measurement should be conducted through the coating. In this paper the coating influence on ultrasonic thickness measurement result was analysed and quantified by measuring the thickness of base material over the coating in repeatability conditions. In order to investigate the coating thickness impact of measurement component, measurements were conducted on prepared test specimen of steel. Extended measurement uncertainty of selected ultrasonic thickness measurement system was estimated.
\end{abstract}

Keywords: ultrasonic thickness measurement; measurement uncertainty; coating influence; Monte Carlo simulation

\section{Introduction}

Coating refers to a layer of material that is naturally or artificially created on the surface, or is applied with some process on structurally different basic materials for the purpose of achieving the appropriate technological and decorative properties. The purpose of the protective coatings and coatings in general is to protect the material of the structures for a long time against harmful environmental impacts, such as corrosion, abrasion, erosion or cavitation, from the appearance of fatigue, cracks, fractures and creases, swelling and cracking, destructive biological factors, damage to the light, or thermal radiation.

Non Destructive Testing methods are frequently used for testing the materials to verify components ability and conformance to accomplish with expected requirements. Today, numerous NDT methods are used for evaluating structural integrity where testing results are compared with expected criterion and decision is made whether or not to continue the safe work. 
NDT methods have been used widely in science and industry such as petroleum and mechanical engineering, ship building, aircraft, railway, power station, gas pipeline. In mentioned industries mostly used materials are steel and aluminium as a material, which involves processes such as welding, casting, forging or machining during construction [1-4]. The quality control which include testing methods commonly is divided into the two sequences known as preservice and in-service inspection that are applied before and during exploitation as a tool for integrity assessment.

Ultrasonic thickness measurement (UTM) is important NDT technique which is used during the production process of component/structure and for the periodic inspection of their integrity during the lifetime. The UTM is commonly used for monitoring thickness of pressure vessels and other kind of components with a coating that mostly cannot be removed from the surface.

The UTM as a technique provides quantitative information about component thickness and so often is referred as a metrology method. For the purpose of accreditation of the UTM all laboratory must fulfil the standards recommended i.e. for the UTM requirements of the standards EN 14127 [5], ISO/IEC 17025 [6] and guideline EA 4/15 [7]. The guideline EA 4/15 defines differences between quantitative, quantitative and semi quantitative NDT results. In that sense the laboratory must identify and control qualitative or semi-quantitative factors which contribute to measurement uncertainty. Furthermore, for the UTM the guideline EA 4/15 requires estimation of measurement uncertainty as the measuring results are shown quantitatively and belongs to the area of metrology activities.

Nowadays, present measuring routine does not take into account the accuracy and precision of ultrasonic thickness measurement and complex synergistic effect of individual influential elements has still not been explored [8]. Furthermore, ultrasonic thickness measurement results are often displayed without associated measurement uncertainty.

Previous investigations were based on researching the influence of individual elements of ultrasonic measurement system, but literature does not describe the synergy effect of selected parameters in the measurement system. The couplant influence on the measurement of the amplitude height have been studied by Budenkov and colleagues [9] and the quantification of couplant thickness influence on measurement result was investigated by Mihaljević and colleagues [10].

Ultrasonic velocity is an important acoustic parameter in material characterization and as an impact factor is a subject of many authors research. Consequently, numerous studies have been conducted with the scope to investigate the changes of ultrasonic velocity in a variety of materials, and thus showed how the changes in the microstructure reflect the differences in propagation speed of the ultrasonic pulses [11-13]. The changes in the microstructure reflect the differences in propagation speed of the ultrasonic pulses what was the scope of investigation of Gur et al. [14]. They measured the differences in the ultrasonic velocity in material caused by changes in microstructure. The changes of ultrasonic velocity in the material as a function of the temperature changes was investigated by several authors [15, 16]. But the changes of ultrasound velocity when measuring is conducted through coatings where errors will occur as a result of the differing sound velocities of the coating and the test object are not described. In this paper research was focused on quantification the coating influence on ultrasonic thickness measurement results.

\section{Design and methodology for the analysis}

Ultrasonic thickness measurement is based on measuring the time-of-flight of ultrasonic pulse travelling through the object. Mentioned principle, also called Pulse-Echo technique, commonly uses four measurement modes prescribed in standard EN 14127 (Fig. 1). The most frequently used mode is the Mode 3. Mode 3 is a principle based on measuring the transit time between the two consecutive ultrasonic pulses reflected from the test object backwall.
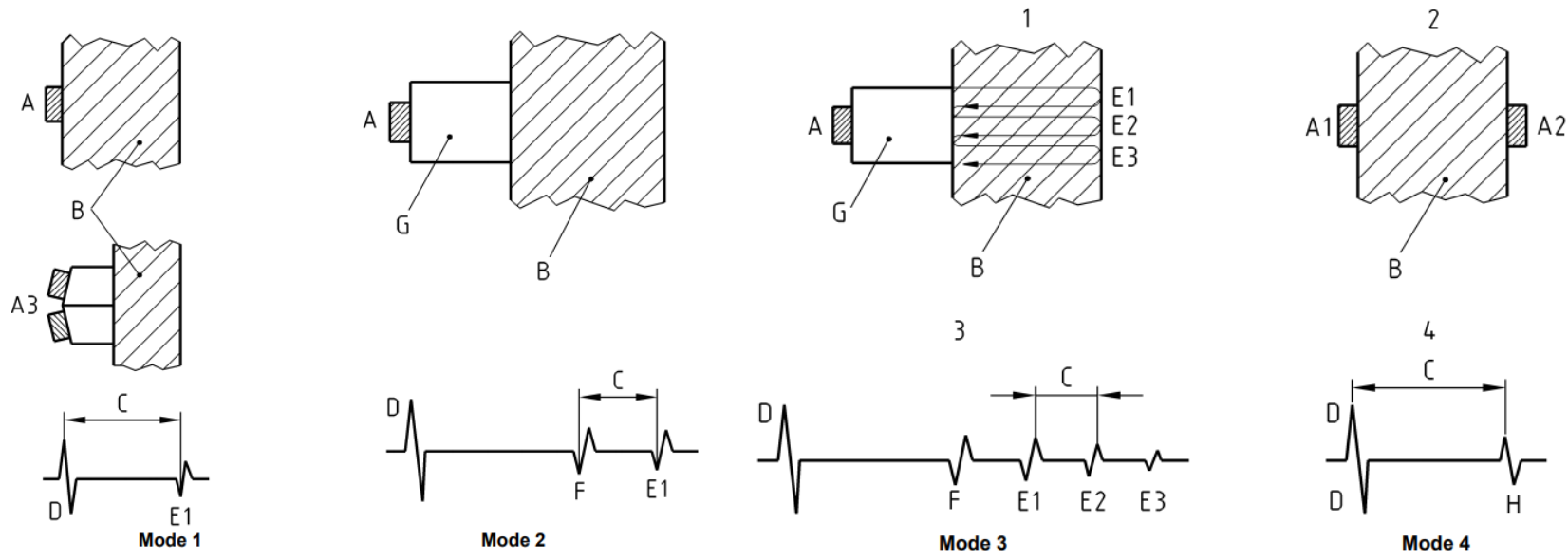

3
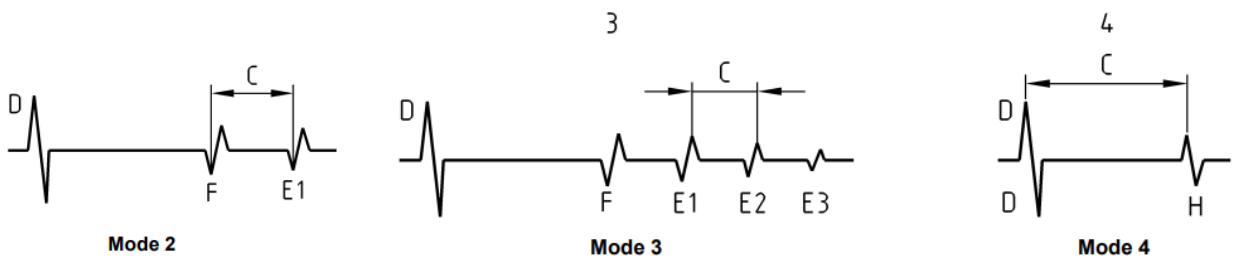


$\begin{array}{llll}\text { A } & \text { Transmit/Receive probe } & \text { D } & \text { Transmission pulse indication } \\ \text { A1 } & \text { Transmit probe } & \text { E1 to E3 } & \begin{array}{l}\text { Backwall echoes } \\ \text { Interface echo }\end{array} \\ \text { A2 } & \text { Receive probe } & \text { F } & \text { Delay path } \\ \text { A3 } & \text { Double transducer probe } & \text { G } & \text { Received pulse } \\ \text { B } & \text { Test object } & \text { H } & \end{array}$

Fig. 1. Ultrasonic measurement modes [6]

Measurement modes prescribed in standard EN 14127 are not the only modes of measurement, since manufacturers develop specific measurement principles to obtain more accurate measurement results. In this research the measurements were conducted in order to analyse the coating thickness influences on the ultrasonic thickness measurement results. For that purpose the steel plate sample was made with three different coating layers to simulate sufficiently realistic conditions. The thickness of the base material through the coating was measured by using ultrasonic thickness measurement device (DMS2) with numerical display showing the measured value and A-scan presentation (waveform display) and appropriate Top Coat probe (5 MHz). Mentioned ultrasonic system has specific measurement mode of measurement.

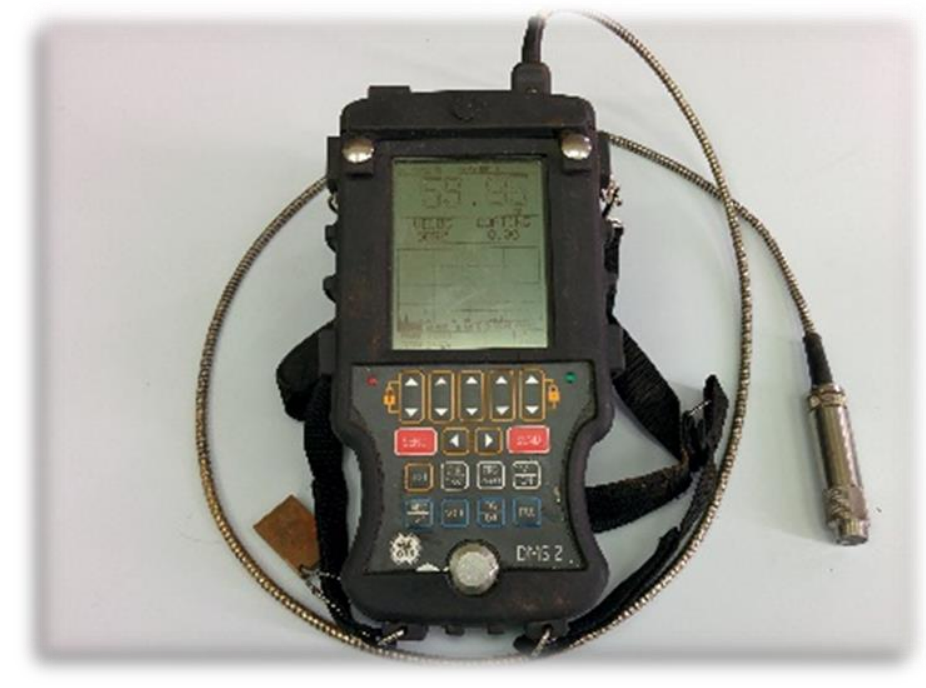

Fig. 2. Ultrasonic measurement system

Sample of steel plate with dimensions of $300 \times 300 \mathrm{~mm}$ and nominal thickness $5 \mathrm{~mm}$ (Fig.3.) is divided into three areas where each coating layer has the following nominal thickness:

Coating layer A - base layer, nominal thickness of $50 \mu \mathrm{m}$

Coating layer B - base layer with an intermediate layer, nominal total thickness of $150 \mu \mathrm{m}$

Coating layer C - base layer with intermediate layer and covering layer, nominal total thickness of $200 \mu \mathrm{m}$

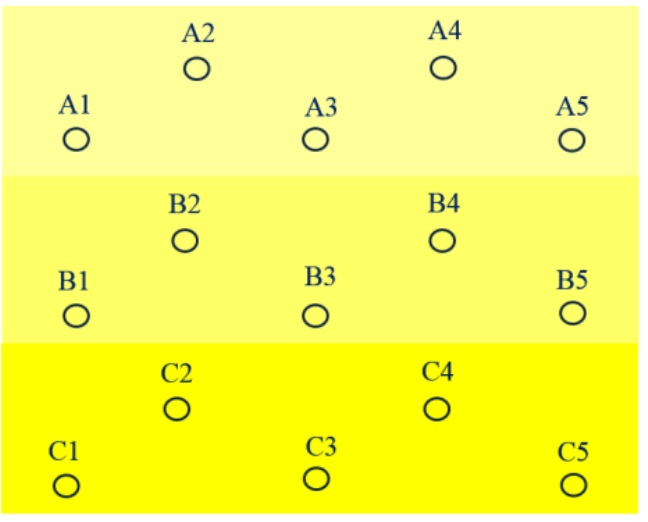

Fig. 3. Three areas and measurement points on the sample plate

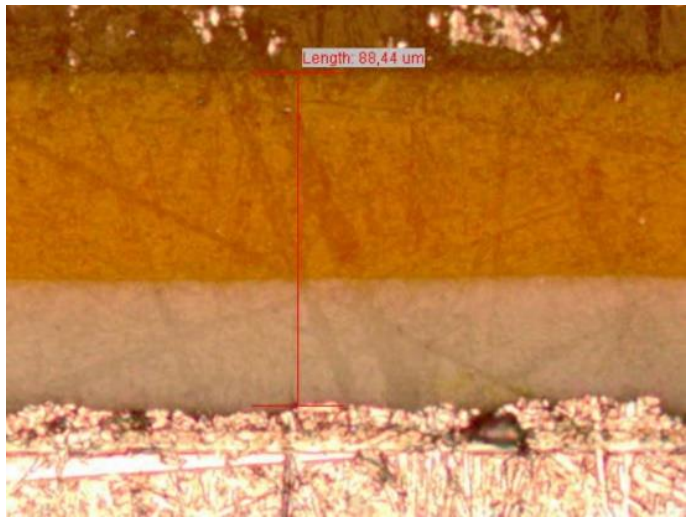

Fig. 4. Determination of the coating thickness layer 
In the practice nominal and real coating layer thickness can differ what contributes to the uncertainty of ultrasonic thickness measurement result. Therefore, coating layer thicknesses were determined by using a microscope on prepared samples which were cut out from the sample of steel plate and prepared for cross section measurement (Fig.4.). These are also checked with coating thickness gages. Measurements of coating layer thicknesses using a microscope was conducted in three different points. The results with related arithmetic means $(\bar{X})$ and standard deviations $(s)$ are given in Table 1.

\begin{tabular}{|c|c|c|c|}
\hline $\boldsymbol{\mu m}$ & \multicolumn{3}{|c|}{ specimen M1 } \\
\hline & area A & area B & area C \\
\hline 1. & 65,13 & 126,57 & 188,92 \\
\hline 2. & 57,27 & 138,91 & 194,14 \\
\hline 3. & 71,88 & 152,12 & 202,17 \\
\hline $\bar{x}$ & $\mathbf{6 4 , 7 6}$ & $\mathbf{1 3 9 , 2}$ & $\mathbf{1 9 5 , 0 7}$ \\
\hline $\mathrm{S}$ & 7,3 & 12,7 & 6,67 \\
\hline
\end{tabular}

Table 1. Coating thickness measurement results

From the results of coating thickness measurement it is obvious that there is a real possibility that non-uniform coating thicknesses contributes to the greater deviation of measurement results. With the scope to minimize the deviations, measurements were conducted on five measurement places on each coating layer area with three repeated measurements.

\section{Measurement results}

The same measurement principle was applied on all three areas of layer thicknesses. For each measurement levels of coating the arithmetic means $(A M)$ of repeated measurements was determined with the estimated variance i.e. standard deviation $(s(d))$ of repeated measurements. Measurement results for each of the 5 measurement points on three layer areas $\mathrm{A}, \mathrm{B}$ and $\mathrm{C}$ are given in Table 2.

\begin{tabular}{|c|c|c|c|c|c|}
\hline $\begin{array}{l}\text { Measurement } \\
\text { points }\end{array}$ & $\begin{array}{c}\text { Base material } \\
\text { thickness results, } \\
\mathrm{mm}\end{array}$ & $\begin{array}{l}\text { Measurement } \\
\text { points }\end{array}$ & $\begin{array}{c}\text { Base material } \\
\text { thickness results, } \\
\mathrm{mm}\end{array}$ & $\begin{array}{l}\text { Measurement } \\
\text { points }\end{array}$ & $\begin{array}{c}\text { Base material } \\
\text { thickness results, } \\
\mathrm{mm}\end{array}$ \\
\hline \multirow{3}{*}{ A1 } & 4,97 & \multirow{3}{*}{ B1 } & 4,98 & \multirow{3}{*}{$\mathrm{C} 1$} & 5,01 \\
\hline & 4,95 & & 4,98 & & 4,99 \\
\hline & 4,88 & & 4,90 & & 4,90 \\
\hline \multirow{3}{*}{ A2 } & 4,99 & \multirow{3}{*}{ B2 } & 5,04 & \multirow{3}{*}{ C2 } & 5,04 \\
\hline & 4,97 & & 4,99 & & 5,01 \\
\hline & 4,94 & & 4,92 & & 4,92 \\
\hline \multirow{3}{*}{ A3 } & 4,98 & \multirow{3}{*}{ B3 } & 5,06 & \multirow{3}{*}{ C3 } & 5,04 \\
\hline & 4,94 & & 5,02 & & 4,99 \\
\hline & 4,89 & & 4,95 & & 4,92 \\
\hline \multirow{3}{*}{ A4 } & 4,99 & \multirow{3}{*}{ B4 } & 5,01 & \multirow{3}{*}{$\mathrm{C} 4$} & 5,01 \\
\hline & 4,97 & & 4,99 & & 4,98 \\
\hline & 4,88 & & 4,89 & & 4,90 \\
\hline \multirow{3}{*}{ A5 } & 4,99 & \multirow{3}{*}{ B5 } & 5,04 & \multirow{3}{*}{ C5 } & 5,05 \\
\hline & 4,98 & & 5,02 & & 5,00 \\
\hline & 4,91 & & 4,94 & & 4,90 \\
\hline$A M$ & 4,95 & $A M$ & 4,98 & $A M$ & 4,98 \\
\hline$s(d)$ & 0,041 & $s(d)$ & 0,054 & $s(d)$ & 0,055 \\
\hline
\end{tabular}

Table 2. Ultrasonic thickness measurement results 
With the scope to quantify coating thickness influences on the ultrasonic thickness measurement results Monte Carlo simulation is used as a probabilistic numerical algorithm. Monte-Carlo simulation is a statistical simulation based on the random events [17]. Each random event generated represents one possible experimental set-up outcome. Using the appropriate probability density function (PDF) and random number generators the distribution of outcomes is made sufficiently realistic [18]. For the ultrasonic thickness measurement system mathematical model was formulated as follow [8]:

$$
d=\frac{\mathrm{t}_{\mathrm{TOF}} \cdot V_{\mathrm{cal}}}{2} \cdot\left(1+\frac{V_{\mathrm{mat}}-V_{\mathrm{cal}}}{V_{\mathrm{cal}}}\right)+\delta d_{\mathrm{c}}
$$

where are:

$d$... thickness of the measured component

$t_{\mathrm{TOF}} \ldots$ time-of-flight of the ultrasonic pulse

$v_{\text {cal }} \ldots$ L-wave velocity set on the device

$v_{\text {mat }} \ldots$ L-wave velocity in the material

$\delta d_{\mathrm{c}} \ldots$ the impact of coating layer thicknesses

In the case of selected UTM system, estimation of coating thickness impact on the ultrasonic thickness measurement results is conducted by using MCS in the software package Matlab.

The probability density function of output values $g(d)$ was obtained with $\mathrm{M}=100000$ simulations (Fig. 5) for the unfavourable case i.e. the results with related arithmetic mean $(\bar{x})$ and standard deviation $(s)$ for real coating layer thickness of $195 \mu \mathrm{m}$. Estimated standard deviation of output values $d$ is $0,05403 \mathrm{~mm}$.

$$
\left(Y_{0.025}=4,89405 \mathrm{~mm} ; Y_{0.975}=5,106 \mathrm{~mm}\right) \text { with, } \mathrm{P}=95 \% \text {. }
$$

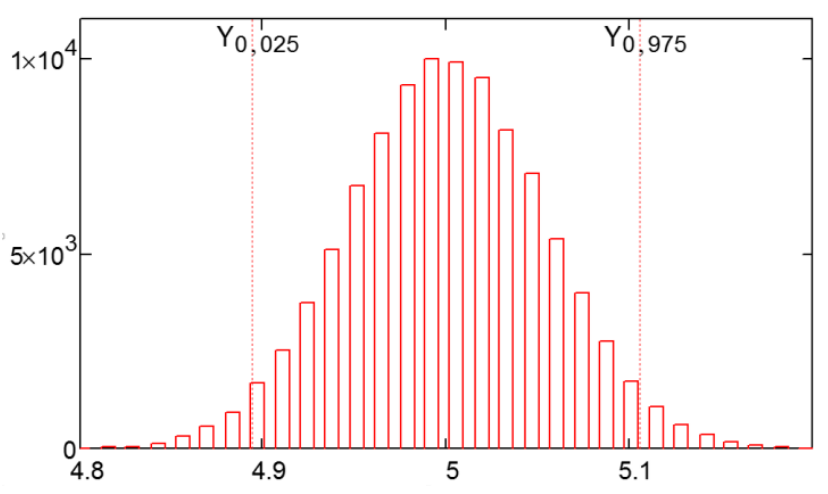

Fig. 5. Probability density function $g(d)$

Probability density function $g(d)$ presents normal distribution. Extended measurement uncertainty of ultrasonic wall thickness measurement involving coating thickness influence on the ultrasonic thickness measurement results equals:

$$
\mathbf{U}(d)=0,105 \mathrm{~mm} ; \text { with } \mathbf{k}=\mathbf{2} \text { and } \mathbf{P}=\mathbf{9 5 \%}
$$

\section{Conclusion}

In the process of the ultrasonic thickness measurement the guideline EA 4/15 requires estimation of the measurement uncertainty as UTM is a quantitative NDT method. It is well-known that each measuring system is influenced by various factors which, by its significance, can more or less affect the accuracy and precision of the obtained results. Geometry of the measurement component is one of the most important parameters that could undermine the confidence in the ultrasonic thickness measurement results. Unfortunately, measurement result of ultrasonic thickness measurement are often displayed without associated measurement uncertainty. Commonly UTM is used to estimate the remaining thickness of the components with a coating that should not be removed from the surface. Furthermore, so often the influence of coating on ultrasonic thickness measurement results is neglected.

In accordance with guideline EA 4/15 and standard ISO/IEC 17025 the coating influence on ultrasonic thickness measurement results was analysed and quantified for the selected ultrasonic measurement system. Monte Carlo simulation is applied to quantify the contribution of coating layer thickness on the process of ultrasonic thickness measurement and the method for quantification was proposed. 
Extended measurement uncertainty of ultrasonic measurement wall thickness involving coating thickness influence on the ultrasonic thickness measurement results equals $0,105 \mathrm{~mm}$ (with $\mathrm{k}=2$ and $\mathrm{P}=95 \%$ ). Obtained extended measurement uncertainty refers to the selected ultrasonic measurement system.

In existing practice there is no enough consideration about the accuracy and precision of ultrasonic thickness measurement and a complex synergy effect of individual influential elements is still not investigated.

In potential further research the investigation should be focused on quantification of the influence of measurement mode in correlation to coating layer on ultrasonic thickness measurement results since in existing practice a complex synergy effect of measurement mode are not yet investigated.

\section{References}

[1] Xuefei, G.; Jingda, Z.; Shaohu, Z.; Rasselkordeb, E.M. \& Wahee, A. (2014). Probabilistic modelling and sizing of embedded flaws in nondestructive inspections for fatigue damage prognostics and structural integrity assessment. NDT \& E International, Vol. 61, pp. 1-9

[2] Pechacek, F. \& Charbulova, M. (2010). Ultrasound Influence in Hole Grinding Process to Al203 Material, Annals of DAAAM for 2010 and Proceedings of 21st International DAAAM Symposium, 20-23rd October, Zadar, Croatia, ISSN 1726-9679, ISBN 978-3-901509-73-5, Katalinić, B. (Ed.), DAAAM International Vienna, Vienna, Austria

[3] Widmaier, T.V.E.; Pirttiniemi, J.T.; Kiviluoma, P.J.; Porkka, E.A. \& Kuosmanen, P.O. (2011). Ultrasonic measurement based modelling of chilled cast iron thermos roll. Annals of DAAAM for 2011 \& Proceedings of the 22nd International DAAAM Symposium, 23-26th October, Vienna, Austria, ISSN 1726-9679, ISBN 978-3901509-83-4, Katalinić, B. (Ed.), DAAAM International Vienna, Vienna, Austria

[4] Nik, M.G.; Mohammad R.; Movahhedy, M.R. \& Akbari, J. (2012). Ultrasonic-Assisted Grinding of Ti6Al4V Alloy, Proceedings of a meeting, 5th CIRP Conference on High Performance Cutting 2012, 4-7th June, Zurich, Switzerland, ISSN: 2212-827, ISBN: 978-1-62748-510-4, Wegener, K. (Ed.), Elsevier B.V., Amsterdam, Netherlands

[5] EN 14127:2011 (2011). Non-destructive testing - Ultrasonic thickness measurement

[6] ISO/IEC 17025:2017. General requirements for the competence of testing and calibration laboratories.

[7] EA4/15 (2015). Accreditation for Non-Destructive Testing

[8] Mihaljević, M. (2015). Measurement uncertainty estimation of the ultrasonic thickness measurement. Ph.D. Dissertation, Quality Department, University of Zagreb, Zagreb, Croatia

[9] Budenkov, G.A.; Nedzvetskaya, O.V.; Shishkina, S.I. \& Polyankin G.A. (2000). Stabilization of Acoustic Coupling for Ultrasonic Testing, Russian Journal of Nondestructive Testing, Vol. 36, No.12, pp 910 - 915, ISSN 1061-8309

[10] Mihaljevic, M.; Cajner, H.; Runje, B.; Markučič, D. \& Keran Z. (2017). Analysis of the couplant influence on the ultrasonic thickness measurement of the steel grade S355J0, Materialwissenschaft und Werkstofftechnik banner, Vol. 48, No. 8, pp 803-313, ISSN:1521-405

[11] Keran, Z.; Mihaljević, M.; Runje, B. \& Markučič, D. (2017). Ultrasonic testing of grain distortion direction incold formed aluminium profile, Achive of Civila and Mechanical Engineering, Vol. 17, No. 2, pp 375-381, ISSN 16449665

[12] Bustillo, J.; Achdjian, H.; Arciniegas, A. \& Blanc, L. (2017). Simultaneous determination of wave velocity and thickness on overlapped signals using Forward Backward algorithm. NDT \& E International, Vol 86, pp.100-105

[13] Loosvelt, M. \& Lasaygues, P. (2011). A Wavelet-Based Processing method for simultaneously determining ultrasonic velocity and material thickness, Ultrasonics, Vol. 51, pp 325-339,

[14] Gur, C.H. \& Tuncer, O.B. (2005). Characterization of microstructural phases of steels by sound velocity measurement, Materials Characterization, Vol. 55, No. 2, pp 160 - 166, ISSN 1044-5803

[15] Burrows, S.E.; Fan, Y. \& Dixon, S. (2014). High temperature thickness measurements of stainless steel and low carbon steel using electromagnetic acoustic transducers, NDT\&E International, Vol. 68, pp 73-77, 2014. ISSN 0963-8695

[16] Periyannan, S. \& Balasubramaniam, K. (2014). Temperature Gradients and Materials Properties Measurements using Ultrasonic Guided Waves, 11th European Conference on NonDestructive Testing, Prague, Czech Republic

[17] Siebert BRL (2001). Monte-Carlo Methods: Scope and Limitations, 160 ${ }^{\text {th }}$ PTB Seminar, Braunschweig, 18-19 June 2001

[18] Markučič, D.; Runje, B.; \& Stepanić, J. (2011). Assesment of measurement uncertainty in modelled ultrasonic thickness measurement. Materialprufung, Vol.53, No.4, pp. 233-237 